\title{
Establishing species boundaries and new taxa among fungi: recommendations to resolve taxonomic ambiguities
}

\author{
Jeewon $\mathbf{R}^{1^{*}}$, Hyde $\mathrm{KD}^{2}$ \\ ${ }^{1}$ Department of Health Sciences, Faculty of Science, University of Mauritius, Reduit, Mauritius, 80837. \\ ${ }^{2}$ Center of Excellence in Fungal Research, Mae Fah Luang University, Chiang Rai 57100, Thailand
}

Jeewon R, Hyde KD 2016 - Establishing species boundaries and new taxa among fungi: recommendations to resolve taxonomic ambiguities. Mycosphere 7 (11), 1669-1677, Doi 10.5943/mycosphere/7/11/4

\begin{abstract}
Accurate identification and demarcation of taxa has far reaching implications in mycology, especially when plant pathogens are involved. Yet few publications have seriously proposed recommendations as to how to delineate species boundaries. Morphology, with all its taxonomic disparities, has been the main criterion upon which current fungal species concepts are based and morphologically defined species make up the largest number of named species. Although phylogenomic based studies arguably offer novel insights into classification at higher taxonomic levels, relationships at the species level and recognition of species remain largely controversial and subject to different interpretations. Our recommendations herein will provide a more rational framework based on scientific data on how to delineate species and establish a new taxon.
\end{abstract}

Key words - DNA sequence data - Fungal species concepts - Interspecific variability Morphological discrepancies - Phenetics - Phylogenetics - Ribosomal and protein genes Taxonomic perceptions

\section{Introduction}

Undeniably it is very complex to define a fungal "species". There are numerous disagreements regarding acceptable criteria to delineate species, whether it is based on morphological, biological, ecological or phylogenetic grounds (Vialle et al. 2013, Vellinga et al. 2015). With respect to fungal taxa, taxonomists find it difficult to apply concepts and segregate species. Some find it even more problematical to establish a new species. This is because of the high degree of phenotypic plasticity and homologous sequence data, the polyphyletic nature of species, as well as prevalence of different asexual morphs for similar taxa (Jeewon et al. 2002, 2003, Shenoy et al. 2010, Desjardin \& Perry 2015, Hyde et al. 2016). Taxonomists, motivated by recent developments in DNA sequence analyses have incorporated phylogenetic data analyses to gain insights into evolutionary relationships (e.g Manamgoda et al. 2011, Schoch et al. 2012, Jeewon et al. 2013). Seifert \& Rossman (2010) proposed taxonomic practices when describing new species, but currently no unified and standardized concept or recommendations have been advocated for differentiating species or establishing new species. It has therefore been incumbent upon taxonomists to define, describe or delineate novel or similar taxa based on phenotypic or molecular features, using their own ideas. Contrary to many expectations, taxonomists still view delineating a new or similar taxon from an existing one, a dilemma. 
Fungal taxonomy has witnessed a sudden explosion in the number of new taxa over the last two decades and given the recent trends in the discovery of new taxa in China, Thailand and Sri Lanka (e.g Karunarathna et al. 2012, Nguanhom et al. 2015, Wu et al. 2016, Doilom et al. 2017, Thambugala et al. 2017, Zhou et al. 2016a, b), a larger number of new species can be expected to be introduced within a few years. With further investigations, we anticipate the number to rise and certainly previous fungal diversity estimates should need revising. Currently phenotypic similarities or differences are evidently incapable of keeping pace with the high levels of diversity, while partial genomic sequence analyses have been used at random with no established and accepted guidelines for fungal species delineation (Ariyawansa et al. 2015, Thambugala et al. 2015). The question arises as to whether we are adopting a scientific and rational approach to diagnose species.

Vellinga et al. (2015) proposed guidelines for introducing new fungal genera, but at the species level, there is no standardized agreement. In this paper, we provide a brief on the major taxonomic problems that preoccupy taxonomists when segregating or defining a new species and propose recommendations as to what mycologists should consider, when demarcating species or establishing a new taxon within a genus.

\section{Can DNA based phylogeny really substantiate/delineate a new species?}

Mycologists presently give overwhelming importance to molecular data to justify the establishment of a new taxon or assess species relationships (Kodsueb et al. 2007, Swe et al. 2008, Bauer et al. 2015, Maharachchikumbura et al. 2016). Sequencing DNA from part of the ribosomal gene and occasionally from several other genes have been common practice ( $\mathrm{Li}$ et al. 2005, Hu et al. 2007, Hyde et al. 2016). However, our phylogenetic concept sometimes adds no further discriminating power to confirm that a taxon is really new. This is especially true under circumstances where i) phylogenetic resolution is weak, ii) there is inadequate taxon sampling, iii) phylogenies aggregate morphologically unrelated species within the same cluster, iv) DNA sequences analyzed from morphologically distinct species are highly similar and share the same lineage, and v) taxa with similar phenotypic traits are distantly related (e.g with polyphyletic species where morphs are subjected to convergent evolutionary trajectories).

Any phylogeneticist will undoubtedly agree that despite the utility of DNA sequence data from nuclear or protein genes at the higher taxonomic ranks (e.g ordinal, familial and generic level), there are intricacies on its reliability in differentiating species (Shenoy et al. 2006, Jayawardena et al. 2016). Apart from multi-locus sequence analysis, there could be other new genomic or chemotaxonomic approaches that could provide insights into understanding fungal speciation, but these are yet to be explored. The latter, for example, have been useful to differentiate Hypoxylon species (Surup et al. 2014, Kuhnert et al. 2015). There is a need to work out how to incorporate any new molecular findings to complement our existing established morphological system to differentiate species, without further undesirable ambiguities. Even though most taxonomists would advocate the use of multi-locus sequence analysis as largely sufficient (e.g Hunter et al. 2006, Stielow et al. 2015), we would argue that this alone does not provide necessary information to better understand fungal speciation or reliable markers for species delineation. For many species already described, there is no culture available for DNA sequence comparison, or in many cases, fungal taxa collected failed to grow in culture possibly due to the use of highly artificial and selective media (Duong et al. 2006, Jeewon \& Hyde 2007). Direct DNA extraction and PCR from fruiting bodies have been quite challenging, but has been successful (Izumitsu et al. 2012). There is a dire need to seek, design and develop rapid, reliable and cost effective methods that could overcome these problems.

A widely-accepted concept of speciation (formation of new and distinct species in the course of evolution) is connected to barriers to gene flow, i.e. reproductive isolation (Giraud et al. 2008). The more geographically distant a species is, the more they acquire genetic differences and this eventually leads to new species with time. There are, however, major problems with this concept in fungal taxonomy: i) many fungi spend most of their life history reproducing asexually with limited genetic exchange; ii) many asexual fungi are polyphyletic in nature resulting in unclear 
evolutionary relationships (Wang et al. 2007); and iii) it is unknown how much time divergence there should be to decide that adequate genetic differences have occurred to warrant species status. Recent studies have demonstrated the feasibility of adopting divergence time estimates from molecular sequence data at different taxonomic ranks (Zhao et al. 2016), but how far such a strategy would work at species level remains to be properly investigated. Can we conclusively assign a taxon a new species status based on slight differences in short nucleotide sequences or should we consider referring them to distinct individuals or populations among same species? There are many unnamed species especially from endophytes and uncultured organisms - if we over rely on a fragment of DNA sequence, then should mycologists move ahead and name all these species? We recommend extreme caution when extracting taxonomic information from these sequences and taxonomists need to remain open to all characters (phenotypic, physiological, mating and chemistry), using phylogenetic information as a guide.

We are far from providing specific barcodes that could reliably identify and segregate fungal species. We aspire towards an integrative taxonomic approach that supports species status. Presently, analyses of whole genomic data are pending for many fungal species and possibly a farfetched idea for many taxonomists. Preliminary studies on the cosmopolitan genus Alternaria have provided meaningful insights into classification (Nguyen et al. 2016). Incorporation of comprehensive molecular data and its cost implication is also an important consideration, especially for developing countries where possibly most new fungi reside (Hyde 2003). How far should taxonomists delve into genomics before identifying, naming and classifying fungi? DNA based phylogenies should not be implemented to displace morphology and it would make more sense for taxonomists to support morphological based classification with DNA sequence data. A simplified, practical and abridged approach with morphological analysis coupled with phylogeny will possibly be a more pragmatic one.

To establish species boundaries or introduce new taxa, there are currently no recommendations for:

a) how much sequence divergence should there be within a fragment of a gene?

b) how many genes should be analysed?

c) how to assess fast, moderate or slow evolving genes and reliability of genetic markers?

d) how phylogenetically distinct a species should be to support its establishment as new?

e) how many taxa should be included in the ingroup for comparative analyses?

f) the minimal phylogenetic statistical support to infer a species relationship?

g) the minimum number of DNA sequences analysed for appropriate taxonomic inferences?

\section{Morphology based discrepancies}

Our discussion in this paper is restricted to fungal organisms mostly at interspecific rather than intraspecific levels. Mycologists most often resort to comparative examination of fruiting bodies and other microscopic characters to delimit taxa or erect new taxa (Swe et al. 2008, Zeng et al. 2012, Doilom et al. 2015). Segregating ascomycete species relies heavily on ascus and ascospore characters (e.g Tang et al. 2007). For instance, Pestalotiopsis and Xylariaceae species are separated based on spore pigmentation (e.g Jeewon et al. 2004, Hu et al. 2007, Daranagama et al. 2015), while Dothideomycetes species might be delineated based on asci shape and presence or absence of pseudoparaphyses (e.g Liew et al. 2000, Li et al. 2016). Among the asexual taxa, such as Pestalotiopsis species, the pigmentation of septa and size of appendages have been the most common morphological aspects considered in species separation and erecting novel taxa (Jeewon et al. 2003, Maharachchikumbura et al. 2011). Common characters among basidiomycetes include details of lamellae (in gills) and mycelial structure of stipe and cap that have commonly been used in interspecific differentiation (Noble et al. 1995, Desjardin \& Perry, 2015).

Technological innovations in microscopy and computer aided digital imaging have enabled mycologists to better use morphometrics in segregating species, especially with variables such as size, colour and shape (Papagianni 2014). It should be mentioned, however, that preserved 
collections, including type specimens, are sometimes in poor condition, making it impossible to see and distinguish important variables (Vizoso \& Quesada 2015). Therefore, fresh collections are needed to circumvent these problems, but obtaining these may be time consuming and labour intensive. Should we compare a taxon with only a single type reference strain, especially where taxonomic records cannot be verified? As compared to our counterparts in botany, virology and bacteriology, taxonomists may have been classifying fungi arbitrarily and segregating species based on slight morphological variants.

Traditional mycotaxonomy involves considerable expertise gained over years of experience (Hyde 2003, Hyde et al. 2013). Thus, there are few specialists to identify the high diversity of fungi so most mycologists resort to molecular taxonomy. Even with DNA based taxonomy, mycologists are already finding it hard to unravel discrete morphs to segregate species (Liu et al. 2010, Jayawardena et al. 2016). Despite all odds, the number of novel species is on the rise, despite the remarkably high degree of morphological and DNA similarity. For most species, taxonomy has always been subjective and thus controversial due to homogeneity in morphology and this resulted in mycologists having their own perceptions towards species. Our morphological based system is reliable when characters are adequate and if the genus contains a few species. In morphologically homogeneous genera such as Colletotrichum, relying only on a few morphs to segregate species is impracticable (Than et al. 2008, Yang et al. 2009, Jayawardena et al. 2016). There are a few instances where there has been major discordance in the taxonomy of Colletotrichum and Alternaria species (Stewart et al. 2014, Sharma et al. 2015, Liu et al. 2016)

Many taxonomic papers have considered the use of specific morphs in species delineation but there have been few attempts to evaluate their phylogenetic significance in a more natural system of classification. The phenomenon of taxa occurring in two states (asexual and sexual) also complicates the mycologist's tasks in classifying species. It has been common practice to name species based on host and pathogenicity, but among two well-known genera such as Diaporthe and Pestalotiopsis, molecular data has not supported such a practice (Jeewon et al. 2004, Udayanga et al. 2014a, 2014b, Maharachchikumbura et al. 2014) and taxonomists should therefore be careful in taxonomic interpretations. Morphological traits are points of convergence between many genetic influences, thus when we examine different morphologies, we are possibly looking at a number of genes that have given rise to such phenotypic traits as compared to analyses of a few genes.

\section{Recommendations for appropriate use of phylogenetic \& morphological data in species delineation}

With so many additions of new fungal species and the transition towards a DNA based approach to identify and delineate existing species, as well as establish new species, we propose the following recommendations, which should be essential to avoid future taxonomic discrepancies:

1) DNA based phylogenies of species should include reference sequences generated from type material (voucher specimens or cultures);

2) Species taxonomy should be based on phylogeny of core genes which have strong phylogenetic signals (e.g ITS regions and at least one protein gene, such as TEF or RPB2 which have sufficient genetic variation as compared to $28 \mathrm{~S}$ or $18 \mathrm{~S}$ rDNA which are rather conserved);

3) Single gene DNA sequences should be initially analysed (e.g. ITS sequences, TEF or RBP2) with a maximum taxon sampling and then supplemented with multi-gene phylogenies with congruent tree topologies;

4) Phylogenetic relationships of novel taxon should include a comparison of at least ITS based phylogeny with a minimum of 4-5 closely related/similar taxa of the same genus, where available;

5) Regions of the ITS sequence (including 5.8S) analyzed should be of a minimum of 450 base pairs with $<1 \%$ position ambiguities. Should DNA sequences from any new taxon be ambiguous, resequencing with reverse and forward primers is essential; 
6) For practical purposes, a minimum of $>1.5 \%$ nucleotide differences in the ITS regions may be indicative of a new species (for fast evolving introns of protein coding genes, a higher percentage in nucleotide differences is warranted). Discrete single nucleotide differences characterizing any taxon should be clearly stated;

7) Phylogeny should support the evolution of a novel clade/lineage for new species or be reasonably phylogenetically distinct from related taxa;

8) To support taxon distinctiveness especially for those with similar phenotypic profiles, there should be reliable statistical support for clade relationship (at least $60 \%$ bootstrap or 0.9 posterior probabilities);

9) Under circumstances where morphs are heterogeneous across species, but there is poor phylogenetic resolution or DNA sequences are rather conserved, estimation of divergence times between species can be obtained to support species splits (estimating speciation dates);

10) Continuous phenotypic variation among species (e.g spore colour, shape/size of ascospores or ascomata) should be treated with caution as many could be influenced by environmental /cultural factors. It is not recommended to segregate or erect new taxon based on minor and statistically insignificant variation in colour or size unless phylogenetic data provides robust support. Any apomorphs (novel evolutionary characters) should be clearly mentioned and supported by phylogenetic data;

11) New taxa at the species level should be diagnosable by a unique combination of character states with at least two-three phenotypic differences from existing species. Minor differences in size and shape should not be the main delimiting criteria for establishing novel taxa;

12) Host association and pathogenicity criteria of segregating species should preferably be supported by molecular evidence on host-specific lineages / host range nonspecialization/opportunists;

13) Major differences in cultural characters among species in specific media that offer clues to possible species delineation should be clearly stated;

14) Novel species descriptions should preferably be based on more than one strain to provide insights into intraspecific phenotypic diversity;

15) Asexual connections and descriptions where appropriate should be included and discussed especially where sexual morphs are used as a basis to differentiate species;

\section{Conclusion}

Mycotaxonomy will be an ongoing challenge. There is no general consensus among taxonomists as to what really defines a species and morpho-taxonomists and phylo-taxonomists can have different viewpoints. Debates surrounding fungal species concepts are still in an embryonic stage and even experienced taxonomists still find it quite intricate to easily diagnose specific morphological attributes for a particular taxon. Key morphological characters, despite sometimes being subtle, should be screened to assign specimens to a reliable taxon. Taxonomists should be able to carefully assess and evaluate morphological variants that can be used to distinguish taxa. Despite the importance of molecular data, over reliance on some may lead to subjective taxonomic decisions. Proper appraisal of phylogenetic inferences without exaggeration of similarities/differences in DNA sequences is essential. Recommendations proposed herein can facilitate mycologists to better interpret phylogenetic assumptions and morphological characters for species delineation. As a cautionary note, in our opinion, to treat a taxon as new, similar or different, an appropriate taxonomic judgement and some common sense is essential. For instance, as mycologists, we are in favour of establishing a new species based on striking morphological differences, despite not having sufficient DNA sequence differences among a few common fragmented genes. Our scientific justifications stem from the fact that there are intricate differences between a gene tree and a species tree and in addition several morphs can be under the influence of many genes which are not really being reflected in the phylogeny. 


\section{Acknowledgements}

The University of Mauritius is acknowledged for support and Rajesh Jeewon thanks Mae Fah Luang University (Chiang Rai, Thailand) for the offer of a short term Visiting Professorship in 2016. K.D. Hyde thanks the Chinese Academy of Sciences, [project number 2013T2S003] for the award of Visiting Professorship for Senior International Scientists at Kunming Institute of Botany as well as Chiang Mai University for a Visiting Professorship.

\section{References}

Ariyawansa HA, Hyde KD, Jayasiri SC, Buyck B et al. 2015- Fungal diversity notes 111-252taxonomic and phylogenetic contributions to fungal taxa. Fungal Diversity 75, 27-274.

Bauer R, Garnica S, Oberwinkler F, Riess K et al. 2015 - Entorrhizomycota: A new fungal phylum reveals new perspectives on the evolution of fungi. PLoS one 10, e0128183. doi:10.1371/journal.pone.012818.

Daranagama DA, Camporesi E, Tian Q, Liu X et al. 2015 - Anthostomella is polyphyletic comprising several genera in Xylariaceae. Fungal Diversity 73, 203-238.

Desjardin DE, Perry BA. 2015 - A new species of Scytinopogon from the island of Príncipe, Republic of São Tomé and Príncipe, West Africa. Mycosphere 6, 434-441.

Doilom M, Shuttleworth LA, Roux J, Chukeatirote E, Hyde KD. 2015 - Botryosphaeriaceae associated with Tectona grandis (Teak) in northern Thailand. Phytotaxa 233, 1-26.

Doilom M, Dissanayake AJ, Wanasinghe DN, Boonmee S et al. 2017 - Microfungi on Tectona grandis (teak) in northern Thailand. Fungal Diversity online, DOI: 10.1007/s13225-0160368-7.

Duong LM, Jeewon R, Lumyong S, Hyde KD. 2006 - DGGE coupled with ribosomal DNA phylogenies reveal uncharacterized fungal phylotypes on living leaves of Magnolia liliifera. Fungal Diversity 23, 121-138.

Giraud T, Refrégier G, Le Gac M, de Vienne DM, Hood ME. 2008 - Speciation in fungi. Fungal Genetics and Biology 45, 791-802.

Hu H, Jeewon R, Zhou D, Zhou T, Hyde KD. 2007 - Phylogenetic diversity of Pestalotiopsis species from Pinus armandii and Ribes spp: evidence from rDNA and Beta tubulin gene phylogenies and morphology. Fungal Diversity 24, 1-22.

Hunter GC, Wingfield BD, Crous PW, Wingfield MJ. 2006 - A multi-gene phylogeny for species of Mycosphaerella occurring on Eucalyptus leaves. Studies in Mycology 55, 147-161.

Hyde KD, 2003 - Mycology in the future in the Asia-Pacific region. Fungal Diversity 13, 59 - 68.

Hyde KD, Udayanga D, Manamgoda DS, Tedersoo L et al. 2013 - Incorporating molecular data in fungal systematics: a guide for aspiring researchers. Current Research in Environmental \& Applied Mycology 3, 1-32.

Hyde KD, Hongsanan S, Jeewon R, Bhat DJ et al. 2016 - Fungal diversity notes 367-490: taxonomic and phylogenetic contributions to fungal taxa. Fungal Diversity 80, 1-270.

Izumitsu K, Hatoh K, Sumita T, Kitade Y et al. 2012 - Rapid and simple preparation of mushroom DNA directly from colonies and fruiting bodies for PCR. Mycoscience 53, 396-401.

Jayawardena RS, Hyde KD, Jeewon R, Li XH et al. 2016 - Mycosphere Essay 6: Why is it important to correctly name Colletotrichum species? Mycosphere 7, 1076-1092

Jeewon R, Hyde KD. 2007 - Diversity and detection of fungi from environmental samples: Traditional versus molecular approaches. In (Eds A. Varma \& R, Oelmuller) Advanced Techniques in Soil Microbiology, 1-11. Soil Biology Series. Springer-Verlag Press.

Jeewon R, Liew ECY, Hyde KD. 2002 - Phylogenetic relationships of Pestalotiopsis and allied genera inferred from ribosomal DNA sequences and morphological characters. Molecular Phylogenetics and Evolution 25, 378-392. 
Jeewon R, Liew ECY, Simpson, JA, Hodgkiss, IJ, Hyde KD. 2003 - Phylogenetic significance of morphological characters in the taxonomy of Pestalotiopsis species. Molecular Phylogenetics and Evolution 27, 372-383.

Jeewon R, Liew, ECY, Hyde KD.2004 - Phylogenetic evaluation of species nomenclature of Pestalotiopsis in relation to host association. Fungal Diversity 17, 39-55.

Jeewon R, Ittoo J, Mahadeb D, Jaufeerally-Fakim Y et al. 2013 - DNA based identification and phylogenetic characterisation of endophytic and saprobic fungi from Antidesma madagascariense, a medicinal plant in Mauritius. Journal of Mycology 781914, 10.

Karunarathna SC, Udayanga D, Maharachchikumbura SN, Pilkington M et al. 2012 - Current status of knowledge of Sri Lankan mycota. Current Research in Environmental \& Applied Mycology 2, 18-29.

Kodsueb R, McKenzie EHC, Lumyong S, Hyde KD, Jeewon R. 2007 - Molecular phylogeny of Aquaticheirospora broccolii; a new synnematous hyphomycete taxon from Thailand and its teleomorphic affinities to Massarinaceae. Botanical Journal of the Linnean Society 155, 283296.

Kuhnert E, Surup, F, Esteban B, Lambert C et al. 2015 - Lenormandins A-G, new azaphilones from Hypoxylon lenormandii and Hypoxylon jaklitschii sp. nov., recognised by chemotaxonomic data. Fungal Diversity 71, 165-184.

Li WJ, Bhat JD, Hyde KD, Wang Y. 2016 - Towards a natural classification of Dothideomycetes 4: The genera Bryopelta, Bryorella, Bryosphaeria, Lophiosphaerella and Maireella (Dothideomycetes incertae sedis) Phytotaxa 176, 028-041.

Li Y, Hyde KD, Jeewon R, Cai L, Vijaykrishna D, Zhang K. 2005 - Phylogenetics and evolution of nematode-trapping fungi (Orbiliales) estimated from nuclear \& protein coding genes. Mycologia 97, 1034-1046.

Liew ECY, Aptroot A, Hyde KD. 2000 - Phylogenetic significance of the pseudoparaphyses in Loculoascomycete taxonomy. Molecular Phylogenetics and Evolution 16, 392-402.

Liu AR, Chen SC, Wu SY, Xu T et al. 2010 - Cultural studies coupled with DNA based sequence analyses and its implication on pigmentation as a phylogenetic marker in Pestalotiopsis taxonomy. Molecular Phylogenetics and Evolution 57, 528-535.

Liu F, Wang M, Damm U, Crous PW, Cai L. 2016 - Species boundaries in plant pathogenic fungi: a Colletotrichum case study. BMC Evolutionary Biology 16, 81-81.

Maharachchikumbura SSN, LD Guo, E Chukeatirote, AH Bahkali et al. 2011 - Pestalotiopsismorphology, phylogeny, biochemistry and diversity. Fungal Diversity 50, 167-187.

Maharachchikumbura SSN, KD Hyde, JZ Groenewald, PW Crous. 2014 - Pestalotiopsis revisited. Studies in Mycology 79, 121-186.

Maharachchikumbura SSN, Hyde KD, Jones EBG, McKenzie EHC et al. 2016 - Families of Sordariomycetes. Fungal Diversity 79, 1-317.

Manamgoda DS; Cai L,Bahkali AH, Chukeatirote E, Hyde KD 2011 - Cochliobolus: an overview and current status of species. Fungal Diversity 51, 3-42.

Nguanhom J, Cheewangkoon R, Groenewald JZ, Braun U et al. 2015 - Taxonomy and phylogeny of Cercospora spp. from Northern Thailand. Phytotaxa 233, 27-48.

Nguyen HD, Lewis CT, Lévesque CA, Gräfenhan T. 2016 - Draft genome sequence of Alternaria alternata ATCC 34957. Genome Announcement 14, 4.

Noble R, Grogan H, Elliott T. 1995 - Variation in morphology, growth, and fructification of isolates in the Agaricus subfloccosus complex. Mycological Research 99, 1453-1461.

Papagianni M. 2014 - Characterization of fungal morphology using digital image analysis techniques. Journal of Microbial \& Biochemical Technology 6, 189-194.

Schoch CL, KA Seifert, S Huhndorf, V Robert et al. 2012 - Nuclear ribosomal internal transcribed spacer (ITS) region as a universal DNA barcode marker for Fungi. Proceedings of the National Academy of Sciences 109, 6241-6246.

Seifert KA, Rossman AY. 2010 - How to describe a new fungal species. IMA Fungus 1, 109-116. 
Sharma G, AK Pinnaka, BD Shenoy. 2015 - Resolving the Colletotrichum siamense species complex using ApMat marker. Fungal Diversity 71, 247-264.

Shenoy BD, Jeewon R, Wu WP, Bhat DJ, Hyde KD. 2006 - Ribosomal and RPB2 DNA sequence analyses suggest that Sporidesmium and morphologically similar genera are polyphyletic. Fungal Biology 110, 916-928.

Shenoy BD, Jeewon R, Wang H, Amandeep K et al. 2010 - Sequence data reveals phylogenetic affinities of fungal anamorphs Bahusutrabeeja, Diplococcium, Natarajania, Paliphora, Polyschema, Rattania and Spadicoides. Fungal Diversity 44, 161-169.

Stewart JE, Timmer LW, Lawrence CB, Pryor BM, Peever TL. 2014 - Discord between morphological and phylogenetic species boundaries: incomplete lineage sorting and recombination results in fuzzy species boundaries in an asexual fungal pathogen. BMC Evolutionary Biology 14, 38 .

Stielow JB, Lévesque CA, Seifert KA, 2015 - One fungus, which genes? Development and assessment of universal primers for potential secondary fungal DNA barcodes. Persoonia 35, 242-263.

Surup F, Kuhnert E, Lehmann E, Heitkämper S et al. 2014 - Sporothriolide derivatives as chemotaxonomic markers for Hypoxylon monticulosum. Mycology 5, 110-119.

Swe A, Jeewon R, Pointing SB, Hyde KD. 2008 - Taxonomy and phylogeny of Arthrobotrys mangrovispora, a new marine nematode-trapping fungal species. Botanica Marina 51, 331338.

Tang AMC, Jeewon R, Hyde KD. 2007 - Phylogenetic relationships of Nemania plumbea sp. nov. and related taxa based on ribosomal ITS and RPB2 sequences. Fungal Biology 111, 392-402.

Thambugala, KM, Hyde KD, Tanaka K, Tian Q et al. 2015 - Towards a natural classification and backbone tree for Lophiostomataceae, Floricolaceae, and Amorosiaceae fam. nov. Fungal Diversity 74, 199-266.

Thambugala KM, Daranagama DA, Phillips AJL, Bulgakov TS et al. Hyde KD. 2017 Microfungi on Tamarix. Fungal Diversity, online, doi:10.1007/s13225-016-0371-z

Than PP, Prihastuti H, Phoulivong S, Taylor PWJ, Hyde KD. 2008 - Chilli anthracnose disease caused by Colletotrichum species. Journal of Zhejiang University Science B 9, 764-778.

Udayanga D, LA Castlebury, AY Rossman, E Chukeatirote, Hyde KD 2014a - Insights into the genus Diaporthe: phylogenetic species delimitation in the D. eres species complex. Fungal Diversity 67, 203-229.

Udayanga D, Castlebury, LA Rossman, AY Hyde KD. 2014b - Species limits in Diaporthe: molecular re-assessment of $D$. citri, D. cytosporella, D. foeniculina and D. rudis. Persoonia 32, 83-101.

Vialle A, Feau N, Frey P, Bernier L, Hamelin RC. 2013 - Phylogenetic species recognition reveals host-specific lineages among poplar rust fungi. Molecular Phylogenetics and Evolution 66, 628-644.

Vellinga EC, Kuyper TW, Ammirati J, Desjardin DE et al. 2015 - Six simple guidelines for introducing new genera of fungi. IMA Fungus 6, 65-68.

Vizoso MT, Quesada C. 2015 - Catalogue of type specimens of fungi and lichens deposited in the Herbarium of the University of Granada (Spain). Biodiversity Data Journal 3, e5204.

Wang HK, Aproot A, Crous PW, Hyde KD, Jeewon R. 2007 - The polyphyletic nature of Pleosporales: An example from Massariosphaeria based on ribosomal DNA and RBP2 gene phylogenies. Fungal Biology 111, 1268-1276.

Wu F, Zhou LW, Dai YC. 2016 - Neomensularia duplicata gen. et sp. nov. (Hymenochaetales, Basidiomycota) and two new combinations. Mycologia 108, 891-898.

Yang YL, Liu ZY, Cai L, Hyde KD et al. 2009 - Colletotrichum anthracnose of Amaryllidaceae. Fungal Diversity 39, 123-146.

Zeng NK, Cai Q, Yang ZL. 2012 - Corneroboletus, a new genus to accommodate the southeastern Asian Boletus indecorus. Mycologia 104, 1420-1432. 
Zhao RL, Zhou JL, Chen J, Margaritescu S et al. 2016 - Towards standardizing taxonomic ranks using divergence times - a case study for reconstruction of the Agaricus taxonomic system. Fungal Diversity 78, 239-292.

Zhou LW, Vlasák J, Qin WM, Dai YC. 2016a - Global diversity and phylogeny of the Phellinus igniarius complex (Hymenochaetales, Basidiomycota) with the description of five new species. Mycologia 108, 192-204.

Zhou LW, Vlasák J, Dai YC. 2016b - Taxonomy and phylogeny of Phellinidium (Hymenochaetales, Basidiomycota): A redefinition and the segregation of Coniferiporia gen. nov. for forest pathogens. Fungal Biology 120, 988-1001. 